OPEN ACCESS

Edited by:

Andy Pereira,

University of Arkansas, United States

Reviewed by:

Nuria Marba,

Consejo Superior de Investigaciones Cientificas (CSIC), Spain

Manoj Kumar,

University of Technology, Sydney,

Australia

*Correspondence:

Lazaro Marín-Guirao maringuirao@gmail.com

Specialty section:

This article was submitted to

Plant Abiotic Stress,

a section of the journal

Frontiers in Plant Science

Received: 21 March 2017 Accepted: 14 June 2017

Published: 29 June 2017

Citation:

Marín-Guirao L, Entrambasaguas L, Dattolo E, Ruiz JM and Procaccini G (2017) Molecular Mechanisms behind the Physiological Resistance to Intense Transient Warming in an Iconic Marine Plant. Front. Plant Sci. 8:1142. doi: 10.3389/fp/s.2017.01142

\section{Molecular Mechanisms behind the Physiological Resistance to Intense Transient Warming in an Iconic Marine Plant}

\author{
Lazaro Marin-Guirao ${ }^{1 *}$, Laura Entrambasaguas ${ }^{1}$, Emanuela Dattolo ${ }^{1}$, Juan M. Ruiz ${ }^{2}$ and \\ Gabriele Procaccini ${ }^{1}$ \\ ${ }^{1}$ Integrative Marine Ecology, Stazione Zoologica Anton Dohrn, Naples, Italy, ${ }^{2}$ Seagrass Ecology Group, Oceanographic \\ Center of Murcia, Spanish Institute of Oceanography, Murcia, Spain
}

The endemic Mediterranean seagrass Posidonia oceanica is highly threatened by the increased frequency and intensity of heatwaves. Meadows of the species offer a unique opportunity to unravel mechanisms marine plants activate to cope transient warming, since their wide depth distribution impose divergent heat-tolerance. Understanding these mechanisms is imperative for their conservation. Shallow and deep genotypes within the same population were exposed to a simulated heatwave in mesocosms, to analyze their transcriptomic and photo-physiological responses during and after the exposure. Shallow plants, living in a more unstable thermal environment, optimized phenotype variation in response to warming. These plants showed a pre-adaptation of genes in anticipation of stress. Shallow plants also showed a stronger activation of heat-responsive genes and the exclusive activation of genes involved in epigenetic mechanisms and in molecular mechanisms that are behind their higher photosynthetic stability and respiratory acclimation. Deep plants experienced higher heat-induced damage and activated metabolic processes for obtaining extra energy from sugars and amino acids, likely to support the higher protein turnover induced by heat. In this study we identify transcriptomic mechanisms that may facilitate persistence of seagrasses to anomalous warming events and we discovered that $P$. oceanica plants from above and below the mean depth of the summer thermocline have differential resilience to heat.

Keywords: heat stress, RNA-seq, Posidonia oceanica, marine plants, comparative transcriptomics, thermal tolerance, transient warming, mesocosms

\section{INTRODUCTION}

Seagrasses are a polyphyletic group of clonal plants of the order Alismatales that have colonized the sea at least on three different occasions along their evolutionary history (Les et al., 1997). In their adaptation to live completely submerged on the marine realm this group of plants converged on a series of structural and physiological modifications, that involved adjustments of their genetic repertoire in respect to terrestrial plants (Wissler et al., 2011; Olsen et al., 2016). Seagrasses lost several characters of the terrestrial counterparts (e.g., absence of stomata) but also gained others typical of macroalgae (e.g., cell wall composition), featuring now clear distinctive attributes and characteristics (Olsen et al., 2016). 
Seagrasses are foundation species that strongly influence the structure and function of littoral ecosystems in most coastal areas worldwide. They form extensive meadows that support diverse food webs and provide numerous ecological functions and socio-economical services rendering them one of the most valuable ecosystems on earth (Costanza et al., 2014). This group of marine plants has been experiencing global decline during the last decades (Waycott et al., 2009), and its loss is expected to be aggravated as a consequence of the on-going climate changes (Koch et al., 2013). Mean atmospheric temperatures are gradually increasing and the frequency of extreme shortterm heat events is growing with consequences on the structural complexity of seagrass meadows and on the associated ecosystem services (Hoegh-Guldberg and Bruno, 2010). Indeed, in recent years temperate seagrass populations have suffered abrupt deterioration triggered by extreme summer temperatures (DíazAlmela et al., 2009; Marbá and Duarte, 2010; Moore et al., 2014; Thomson et al., 2015).

In contrast to terrestrial plants, quite little is known about the effects of heating on seagrasses and almost nothing is known about the tolerance mechanisms these can activate to overcome transient exposures to temperature extremes. Understanding heat tolerance mechanisms in seagrasses will be critical to increase our ability to protect and manage these valuable coastal ecosystems and to estimate their plasticity and potential ability to adapt and persist in an ocean that is experiencing unprecedented changes.

Based on the available information, it is generally accepted that in seagrasses mild increases in water temperature lead to an increase in both the photosynthetic and the respiratory rates (Lee et al., 2007; Koch et al., 2013). Although several tropical species have shown an ability to down-regulate respiration (Collier et al., 2011), the rise of respiration is generally proportionally higher than that of photosynthesis (Lee et al., 2007). This can continue over the physiological optimum of the species, where photosynthesis collapses, causing a major metabolic imbalance and dwindling energy reserves, with potential consequences on the ability of plants to survive and recover after transitory thermal stress. At more extreme temperatures, seagrasses can suffer chronic photosynthetic inhibition by direct damage of photosystems II and/or activation of non-photosynthetic quenching processes (Ralph, 1998, 1999; Campbell et al., 2006; Winters et al., 2011; Pedersen et al., 2016). Under short exposures to these temperature extremes seagrass growth is blocked and mortality induced (Campbell et al., 2006; Collier and Waycott, 2014).

Since global warming alters plant performance by directly affecting processes at molecular, biochemical and physiological level, studying these processes under controlled experimental conditions allows to understand the mechanism that would let seagrasses to endure transitory high ambient temperatures (Leakey et al., 2009). Indeed, the ability to measure genomewide patterns of transcript abundance have provided, in recent years, a new opportunity to improve our understanding of the intrinsic strategies through which seagrasses can respond to global change (Procaccini et al., 2012; Davey et al., 2016). Plastic and adaptive changes of Zostera marina and Z. noltei to warming have been explored using individuals from contrasting latitudinal origins and exposing them to heat stress under controlled conditions (Franssen et al., 2011, 2014; Gu et al., 2012; Jueterbock et al., 2016). The two species featured responses comparable to terrestrial plants, including the induction of heat shock proteins (HSPs), antioxidant enzymes and proteins involved in cell wall fortification ( $\mathrm{Gu}$ et al., 2012; Franssen et al., 2014). However, in both species no clear differences in the expression of genes involved in key processes such as photosynthesis, respiration, lipids synthesis and translation/transcription were detected during the heat exposure, despite the differences in growth and photosynthetic thermal tolerances (Franssen et al., 2014). Geneexpression patterns diverged between the populations of different origin during the subsequent recovery, matching their expected differences in heat tolerance (Franssen et al., 2011). This allowed authors to introduce the concept of transcriptomic resilience as a predictor of thermal adaptation in seagrasses, but limited their ability to identify the molecular mechanisms underlying the physiological tolerance of marine plants to transient heat stress.

In the present work, we aim to explore the molecular response mechanisms of an iconic seagrass species during short periods of anomalous warming. Posidonia oceanica (L.) Delile is endemic for the Mediterranean Sea and ranks amongst the slowestgrowing and longest-lived plants on earth (Arnaud-Haond et al., 2012). The Posidonia genus arises from an independent lineage to that of Zostera (Les et al., 1997), with which it shows sharp differences in the biological and ecological attributes. P. oceanica forms dense and perennial monospecific meadows that extend along a wide bathymetric gradient (from 0 to $40 \mathrm{~m}$ depth) all along the Mediterranean coasts, being considered the climax stage of the Mediterranean sublittoral environment.

The bathymetric distribution of the species and the marked summer stratification of Mediterranean Sea water column forces shallow and deep growing plants to adapt to contrasting environmental conditions. Indeed, shallow and deep portions of $P$. oceanica meadows can harbor distinct genotypes (Migliaccio et al., 2005) and show different physiological strategies and gene expression patterns, as assessed in natural conditions (Dattolo et al., 2014), as result of an adaptive divergence toward the light environment experienced at the two depths (Dattolo et al., 2017). This environmental gradient offers an invaluable opportunity to explore potential acclimation/adaptation mechanisms to thermal stress in seagrasses at a small spatial scale. Within the same population, shallow growing plants experience warmer and more fluctuant temperatures than deep ones. Deep meadow portions of the meadow can experience high temperature during extreme thermal events, although for very short periods. Recent findings indicate that genotypes from shallow areas have higher physiological heat acclimation capacities than deep genotypes of the same meadow, living in a colder and more stable thermal environment (Marín-Guirao et al., 2016). Following this findings, tolerant (shallow) and sensitive (deep) genotypes of the species, were collected from above and below the summer thermocline, in a meadow where genetic disjunction between the two depths was previously reported (Dattolo et al., 2017). Genotypes were exposed for several days to an intense warming event in a mesocosms system and photophysiological and 
transcriptome-wide gene expression analyses were performed after the transient exposure to heat and after a subsequent recovery period. By comparative transcriptomics analysis, we explored genotype's responses to identify mechanisms involved in the tolerance and acclimation of $P$. oceanica to short-term heat events and to provide understanding about seagrasses capacities for plastic and evolved responses to ocean warming. Besides a comprehensive analysis of the transcriptomic profiles of experimental plants, we dig into targeted pathways that are key in acquired thermotolerance in plants (e.g., heat shock proteins and factors, antioxidants, epigenetics) as well as into key physiological processes with known contrasting heat tolerances in the studied species (e.g., photosynthesis and respiration). The objective is to identify transcriptomic traits associated to higher thermal tolerance in seagrasses as well as the potential mechanisms behind the thermal resilience of key physiological processes in the species.

\section{MATERIALS AND METHODS}

\section{Plant Sampling, Genotyping, and Experimental Design}

On October 2014, large P. oceanica plant fragments bearing a high number of connected shoots were collected by divers at $5 \mathrm{~m}$ (shallow) and $25 \mathrm{~m}$ (deep) depth within a continuous meadow off the south-eastern coast of Spain (Isla Grosa; $37^{\circ} 43^{\prime} 40^{\prime \prime} \mathrm{N}$ / $0^{\circ} 41^{\prime} 48^{\prime \prime} \mathrm{W}$ ). Sea water temperature at the sampled meadow annually ranges between $12.94 \pm 0.45^{\circ} \mathrm{C}$ and $28.03 \pm 0.93^{\circ} \mathrm{C}$ with an average temperature for the summer months of July and August of $26.42 \pm 0.64^{\circ} \mathrm{C}$ (Period 2010-2016; Ruiz et al., 2015). Within $2 \mathrm{~h}$ of collection, three shallow and three deep plant fragments were split in two portions of similar size and number of shoots (i.e., 20-25 and 14-17 shoots for shallow and deep fragments, respectively) and transplanted in individual tanks (120 L). Genotyping was carried out following the methods described by Tomasello et al. (2009), to ensure that these fragments represent different genotypes. Briefly, a leaf segment of about $2 \mathrm{~cm}$ was collected from each plant fragment, cleaned of epiphytes with a razor blade and dried in silica gel. Genomic DNA was manually extracted following the standard protocol of the nucleo-spin plant II kit (Macherey-Nagel). Individual multilocus genotypes were assessed by a total of 12 microsatellites and manually compared for assessing identity (Table S1).

Plants were acclimated under their respective environmental conditions as determined in the field at the moment of sampling. Temperature was the same at the two depths, i.e., $24 \pm 0.2^{\circ} \mathrm{C}$, salinity was $37.5 \pm 0.2 \mathrm{ppt}$ and irradiance was $7.2 \pm 0.6$ and $1.9 \pm 0.3 \mathrm{~mol}$ photons $\mathrm{m}^{-2} \mathrm{day}^{-1}$, for shallow and deep plants, respectively. The photoperiod was $8 / 16 \mathrm{~h}$. After 10 days of acclimation in the experimental tanks, harboring one of the two plant fragments of each genotype, water temperature was progressively increased to $32^{\circ} \mathrm{C}$ at a rate $0.5^{\circ} \mathrm{C} \mathrm{h}^{-1}$. The exposure lasted 5 days after which temperature was returned to control levels to allow plants to recover from heat for another 5 days. Plant responses were determined in each tank at the end of both the exposure and the recovery periods. For a more complete description of the experimental system, see Marín-Guirao et al. (2016).

\section{PSII Photochemical Efficiency}

A diving-PAM fluorometer (Walz, Germany) was used to evaluate the maximum quantum yield of PSII $\left(\mathrm{F}_{\mathrm{v}} / \mathrm{F}_{\mathrm{m}}\right)$, a measurement of the photosynthetic efficiency of PSII. For each sample, $F_{\mathrm{V}} / \mathrm{F}_{\mathrm{m}}$ was calculated by determining the minimum fluorescence of whole-night dark-adapted leaves $\left(\mathrm{F}_{0}\right)$ and the maximum fluorescence $\left(\mathrm{F}_{\mathrm{m}}\right)$ when all PSII reaction centers were reduced by a saturation pulse of white light $\left[\mathrm{F}_{\mathrm{v}} / \mathrm{F}_{\mathrm{m}}=\right.$ $\left.\left(\mathrm{F}_{\mathrm{m}}-\mathrm{F}_{0}\right) / \mathrm{F}_{\mathrm{m}}\right]$. Measurements were conducted at the end of the exposure and recovery periods on three shoots per tank (i.e., plant fragment) and then averaged to be used as individual replicates $(n=3)$. Data obtained at each time point were analyzed with factorial ANOVA to explore the effects of the heat shock on PSII functionality, and subsequently subjected to post-hoc Student-Newman-Keuls test, when significant differences were found for the factors $(p<0.05)$.

\section{RNA Extraction and MRNA Sequencing}

A $7 \mathrm{~cm}$ leaf segment from $20 \mathrm{~cm}$ above the ligule of the first mature leaf was collected $(14: 00 \mathrm{~h})$ at the end of the exposure and recovery periods from one randomly selected shoot per tank. Samples were immediately cleaned of epiphytes, dipped into RNA-later and stored at $-80^{\circ} \mathrm{C}$ until total RNA extraction, that was performed using the Aurum Total RNA Kit (Bio-Rad). The quality and quantity of the extractions were assessed by using Nanodrop (Thermo Fisher Scientific) and a 2100 BioAnalyzer (Agilent). Twenty four libraries $(2$ depths $\times 2$ treatments $\times$ 3 replicates $\times 2$ time points) were constructed with TruSeq Stranded mRNA Library Prep Kit (Illumina) and sequenced with a Hiseq1000 platform (Illumina) to generate a total of $776,971,548$ paired-end reads of $101 \mathrm{bp}$ in average ( $>30$ million reads per library; see Table AS1 in Appendix S1).

\section{De novo Transcriptome Assembly}

Quality of raw Illumina sequence data was assessed using FASTQC (v.11.3) software (Andrews, 2010). Raw reads were subjected to a cleaning procedure using Trimmomatic v2.33 (Bolger et al., 2014) and possible post-sequencing ribosomal RNA contamination were eliminated through the local sequence alignment tool SortMeRna v.2.0 (Kopylova et al., 2012) with an E-value cut-off of 1E-20. Using Trinity v.2.0.6 (Grabherr et al., 2011) with in-silico read normalization and default parameters, HQ cleaned reads were assembled into a transcriptome as no reference genome is available for $P$. oceanica. To further assess the quality of the assembly, reads from each library were mapped back to the assembly using Bowtie v.1.1.1 (Langmead et al., 2009). The assembled transcripts with length $\geq 200$ bp were used as the sequence dataset of reference transcripts.

\section{Functional Annotation}

Sequence similarity searches of the Swiss-Prot and NCBI's non-redundant (nr) databases were conducted with BLASTX program (Altschul et al., 1997) with a cutoff E-value of 1E6. Assembled transcripts were also compared against NCBI's 
partially non-redundant nucleotide sequences databases using BLASTN (E-value $<1 \mathrm{E}-6)$. Subsequently, with an integrated use of the Blast2GO v.3 (Conesa et al., 2005) we retrieved Gene Ontology (GO) terms (Ashburner et al., 2000) at an E-value threshold of 1E-6 for transcripts with a positive BLAST hit and additional functional information based on protein domains and motif information through the InterProScan function available in Blast2GO with default settings (Zdobnov and Apweiler, 2001). We also performed enzyme code (EC) annotation for the assembled transcripts and retrieved KEGG maps for the metabolic pathways in which they participate. In situations in which a given gene contained multiple isoforms, the longest one was defined as the gene functional annotation and used in the following analysis.

\section{Gene Expression and Go Enrichment Analyses}

Gene expression analyses were performed using a filtered transcriptome as a reference in order to maintain transcripts that were more strongly supported by the reads. Trinity wrapper run_RSEM.pl (Haas et al., 2013) was used to align reads to the assembled contigs and to select for transcripts that accounted for at least $1 \%$ of the per-component (IsoPct) expression and that met a transcript per million (TPM) cutoff of 1. Illumina reads from each biological replicate were aligned separately to the filtered transcriptome using Bowtie v.1.1.1 (Langmead et al., 2009) and expression of each gene was quantified using the Expectation-Maximization method (RSEM; Li and Dewey, 2011). Differentially expressed genes were determined using the edgeR package (Robinson et al., 2010). Firstly, we selected a stringent cut-off of four-fold (FDR $<0.001$; herein after referred as strongly differentially expressed genes, s-DEGs) to explore overall responses and to examine differences in gene expression in the following pair wise comparisons: (i) all controls vs. all heated plants, to explore the general heat stress response in P. oceanica and; (ii) shallow controls vs. shallow heated plants and deep controls vs. deep heated plants, to study the response to heat of shallow and deep plants, respectively. All the comparisons were performed after both the exposure and the recovery periods. Secondly, DE analysis was broadened to a level of two-fold change (FDR $<0.01$, herein after referred as differentially expressed genes, DEGs) and shallow and deep plants were compared with their controls (ii of the previous analysis) only for specific key physiological processes (i.e., photosynthesis and respiration) involved in contrasting heat tolerances among shallow and deep P. oceanica plants (MarínGuirao et al., 2016). Epigenetic processes, heat shock factors (HSFs), HSPs, and antioxidants production were also considered, due to their important implications in plant thermotolerance (Wahid et al., 2007; Bita and Gerats, 2013).

Principal component analysis (PCA) was conducted using the "prcomp" function within R environment v. 3.2.2 (R Core Team, 2015) and scatter plot of PCA results was generated using the ggplot2 package (Wickham, 2010).

GO enrichment analyses of DEGs were performed using Blast2GO with a threshold FDR-corrected $P$-value from Fisher's exact test, 0.05. Summarization of GO terms based on their semantic similarities was performed on the REVIGO web service (http://revigo.irb.hr/; Supek et al., 2011) and their representation on a $2 \mathrm{D}$ semantic space was generated using the ggplot2 package in $\mathrm{R}$.

To validate results of our sequencing analyses (mRNA-seq), the expression of 12 randomly selected genes was assessed by Reverse Transcription-quantitative Polymerase Chain Reaction (RT-qPCR). We used the same shallow- and deep-RNA samples from the end of the heat exposure period that were utilized for transcriptome sequencing, and followed the methods described in Mazzuca et al. (2013). Complementary DNA was synthetized with the iScriptTM cDNA Synthesis Kit (Bio-Rad). RT-qPCR was performed in triplicate in a Viia7 Real Time PCR System (Applied Biosystem) using Fast SYBR ${ }^{\circledR}$ Green Master Mix (Thermo Fisher Scientific) and analyzed by the $2^{-\Delta \Delta C t}$ method, using L23 and NTUBC as reference controls (Marín-Guirao et al., 2016). All primer sequences used for RT-qPCR are listed in Table S2.

\section{RESULTS}

\section{Effects of Short-Term Heat Stress on PSII Photochemistry}

Exposure of shallow plants for 5 days to the experimental temperature of $32^{\circ} \mathrm{C}$ did not cause any significant alteration on the photochemical efficiency $\left(\mathrm{F}_{\mathrm{v}} / \mathrm{F}_{\mathrm{m}}\right)$. Deep plants, instead, showed a significant reduction $(p<0.001)$ of the $\mathrm{F}_{\mathrm{v}} / \mathrm{F}_{\mathrm{m}}$ ratio, from an average of $0.790( \pm 0.001, \mathrm{SE})$ in controls to 0.749 $( \pm 0.001)$ in heated plants (Figure 1). This reduction was due to a significant $35 \%$ increase in $\mathrm{F}_{0}$, indicating that the applied stress caused PSII inactivation (Brestic and Zivcak, 2013). Photochemical effects disappeared after 5 days of recovery when controls and heated plants from both depths showed similar photochemical efficiencies, with values that in all cases were above 0.780 .

\section{Transcriptome Sequencing and De novo Assembly}

A thorough description of the results derived from the sequencing, de novo assembly and annotation of the transcriptome is provided as supplementary information (Appendix S1). In brief, a total of $697,043,338$ high quality paired-end reads $(89.7 \%$ of initial raw reads) were de novo assembled resulting in 222,548 putative transcripts ( $\geq 200 \mathrm{bp}$ ) with an overall size of $390 \mathrm{Mb}$, an average length of $918 \mathrm{bp}$ and GC percent of $44.5 \%$. On average, $82.7 \%$ of the reads mapped back to the assembly indicating that the transcriptome was a reliable reference. Raw sequence reads were deposited in NCBI Short Read Archive under BioProject ID PRJNA353749 (accession number SRP093709).

\section{General Transcriptomic Response of $P$. oceanica to Heat Stress}

The patterns of gene expression following heat stress was consistent among replicates (i.e., genotypes; Figure 2) and hierarchical cluster analysis of s-DEGs clearly revealed different 

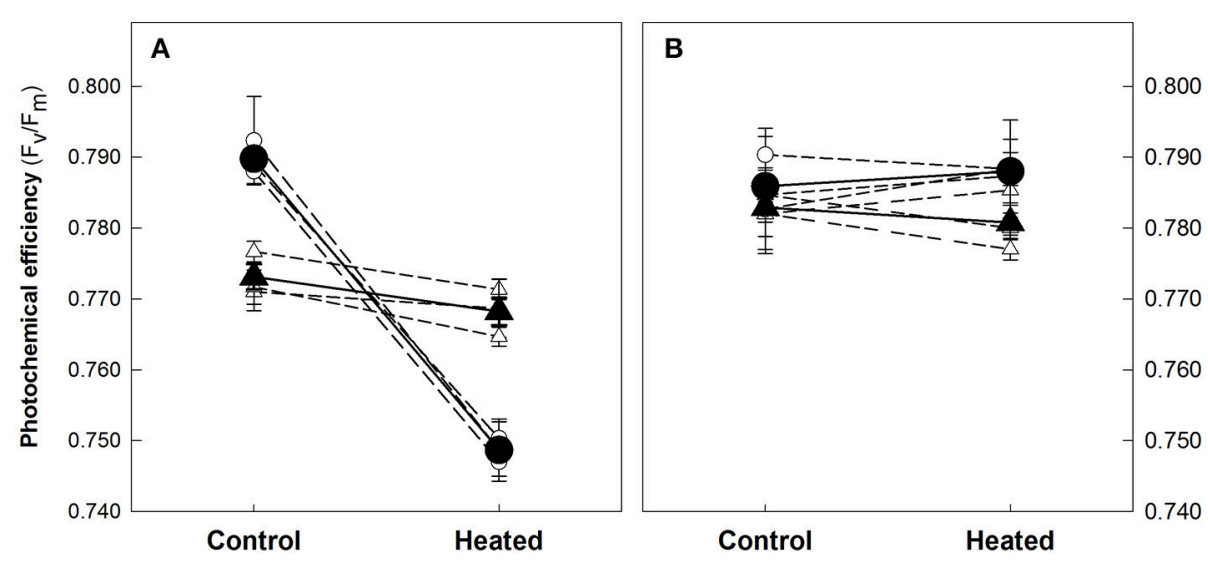

FIGURE 1 | Maximum PSIl photochemical efficiency $\left(F_{v} / F_{m}\right)$ of shallow and deep Posidonia oceanica plants from the control and heat treatments at the end of the heat exposure $(\mathbf{A})$ and recovery $(\mathbf{B})$ periods. Averaged $F_{v} / F_{m}$ values ( \pm standard error) of the three shoots measured in each individual genotype (empty symbols) and the average value of the three replicate genotypes (solid symbols) are represented. Plant's depth is represented with different symbols as showed in the legend.
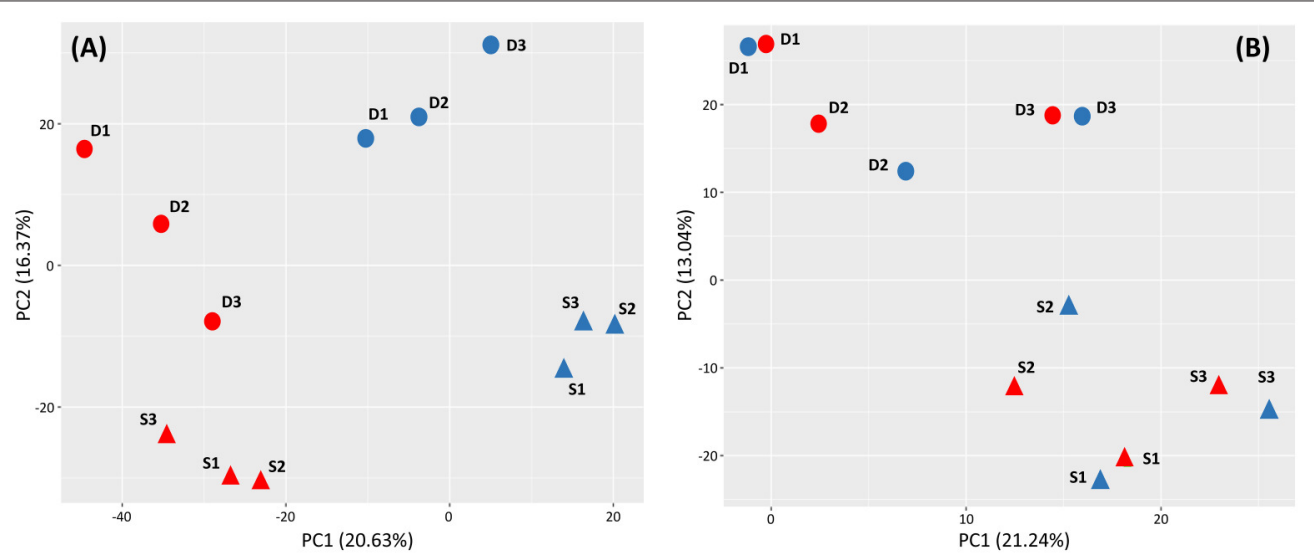

FIGURE 2 | Principal component analyses (PCA) performed with all 72,169 differentially expressed contigs (5\% false discovery rate) found in shallow (triangles) and deep (circles) Posidonia oceanica plants at the end of the heat exposure (A) and recovery (B) periods. Heated and control plants are represented in red and blue, respectively. In parenthesis, the proportion of variance explained by principal components 1 and 2 is represented.

patterns of expression between heated and control plants (pooled across depths; Figure S1).

The comparison among all heated and all control plants showed the largest number of s-DEGs (\#374, Figure 3) among all the other comparisons (i.e., shallow controls vs. shallow heated and deep controls vs. deep heated), with 198 genes upregulated with an average fold change of 6.8 (FC range, 4265). The most highly up-regulated genes were an adenylate cyclase and a photosystem II $10 \mathrm{kDa}$ chloroplastic protein (psbR) associated with the oxygen-evolving complex of PSII (Data S1A). Over-expressed biological functions of up-regulated genes (Fisher test, FDR < 0.05) included among others: (1) responses to stimulus and stress (including heat); (2) DNA and RNA processes (DNA repair, replication, codification, transcription and methylation; gene silencing by RNA, regulation of RNA process); (3) regulation of cellular biosynthetic and metabolic processes and of cell growth and division; and (4) cell wall organization (Data S2A). Down-regulated genes (\#176, Figure 3) for the same comparison were enriched in 41 over-represented biological processes, with the glycerolipid biosynthetic process being the most representative one ( $p=1.05 \mathrm{E}-08$; Data $\mathrm{S} 2 \mathrm{~B}$ ). After a recovery period of 5 days, the comparison "all heated vs. all controls" showed that differences in gene expression almost disappeared since only 15 s-DEGs (all down-regulated, Figure 3) were detected. Genes involved in key processes that could potentially compromise the long-term performance of heated plants after stress cessation were not identified within this set of genes (Data S1B). The most highly down-regulated genes encode for key enzymes of the jasmonic acid biosynthesis pathway (lipoxygenase 5 and allene oxide synthase), which are tightly involved in plant stress responses (Yang et al., 2011). Two genes encoding HSPs and that were previously upregulated during the heat exposure were also identified in this set of genes. 


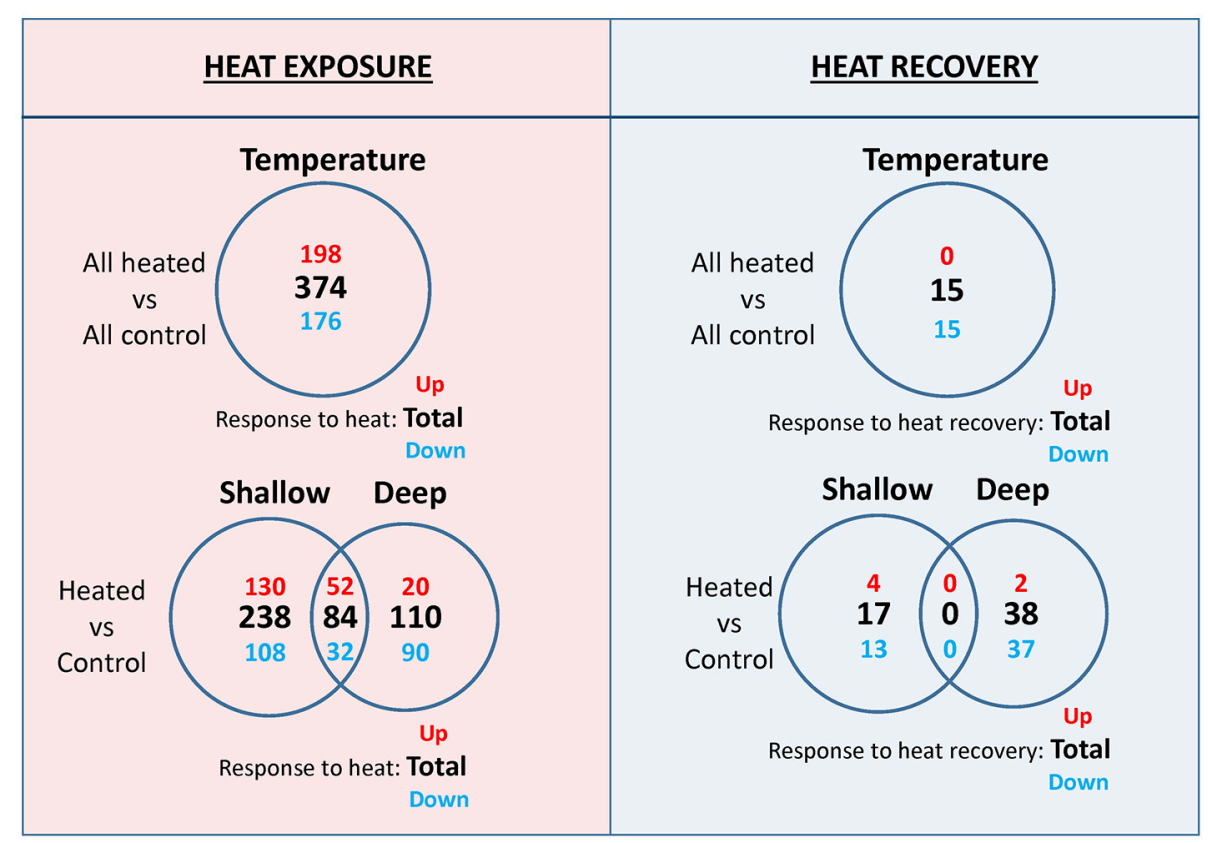

FIGURE 3 | Venn diagram showing the number of strongly differentially expressed genes (s-DEGs; >four-fold change; false discovery rate <0.001) based on temperature, depth, within-depth heat response, and within-treatment depth differences at the end of the heat exposure (left panel) and at the end of the heat recovery (right panel) periods. Bold numbers denote totals, while red and blue numbers indicate, respectively, up-regulated and down-regulated or higher expression in shallow and in deep plants, as indicated in the figure.

\section{Depth-Specific Transcriptomic Response}

In the PCA plot, obtained using normalized expression values, heated and control plants showed the strongest differentiation and were clearly separated along the first axis $(\mathrm{PC1}=20.6 \%$ of the total variance), while PC2 axis (16.4\% of total variance) differentiated shallow from deep plants irrespective of the thermal treatment. The PCA conducted after recovery still differentiated shallow from deep plants (PC2 $=13.04 \%$ of the total variance) whereas it grouped all heated genotypes from both depths with their own controls, indicating their successful recovery (Figure 2). Also in the heatmap derived from hierarchical cluster of s-DEGs, the two main clusters of heated and control plants contained two sub-clusters for shallow and deep plant replicates, respectively (Figure S1). After the recovery period, however, transcriptomic differences due to heat disappeared and all shallow and deep replicates were clustered together irrespective of whether they were previously heated or not.

\section{Shared Transcriptomic Response to Heat Stress between Depths}

There were 84 genes that commonly responded to heat stress in shallow (shallow heated vs. shallow controls) and deep (deep heated vs. deep controls) plants, 52 up-regulated and 32 down-regulated (Figure 3). Common up-regulated genes during heat exposure (Table 1) were involved in protein folding (11 genes), oxidation-reduction processes (3 genes), ubiquination and proteolysis ( 3 genes), membrane and cell wall modification
(2 genes), carbohydrate metabolic processes (2 genes), regulation of cell cycle (1 gene), cyclic phosphorylation (1 gene) and in the heat shock mediated-signaling pathway (1 gene, i.e., serine threonine-protein phosphatase 7; Liu et al., 2007). These common up-regulated genes showed, however, differences in their expression strength and constitutive levels (i.e., normalized contig reads in controls) between shallow and deep plants (Table 1). While the most highly up-regulated genes in shallow plants were involved in protein folding and encode for HSPs, those of deep plants were related to ubiquination (u-box domaincontaining protein 12-like, PUB12) and proteolysis (tripeptidylpeptidase 2, TPP2). Besides a few HSPs, the largest difference in the responsiveness to heat between shallow and deep plants corresponded to chloroplastic polyphenol oxidase A1, which also has higher constitutive level of expression (Table 1) and is likely involved in protecting photosynthesis functioning, increasing stress tolerance in plants (Boeckx et al., 2015). Moreover, in shallow plants $74 \%$ of all common genes showed stronger heat response compared to deep plants and 68\% showed higher constitutive expression (Table 1).

\section{Difference in the Response to Heat Stress between Depths}

Besides the above differences in the set of genes that commonly react to heat, $P$. oceanica plants from different depths also showed other important differences. In the comparison with their own controls ("heated vs. control"), shallow heated plants showed $40 \%$ more s-DEGs than deep plants (322 vs. 194), and the proportion 


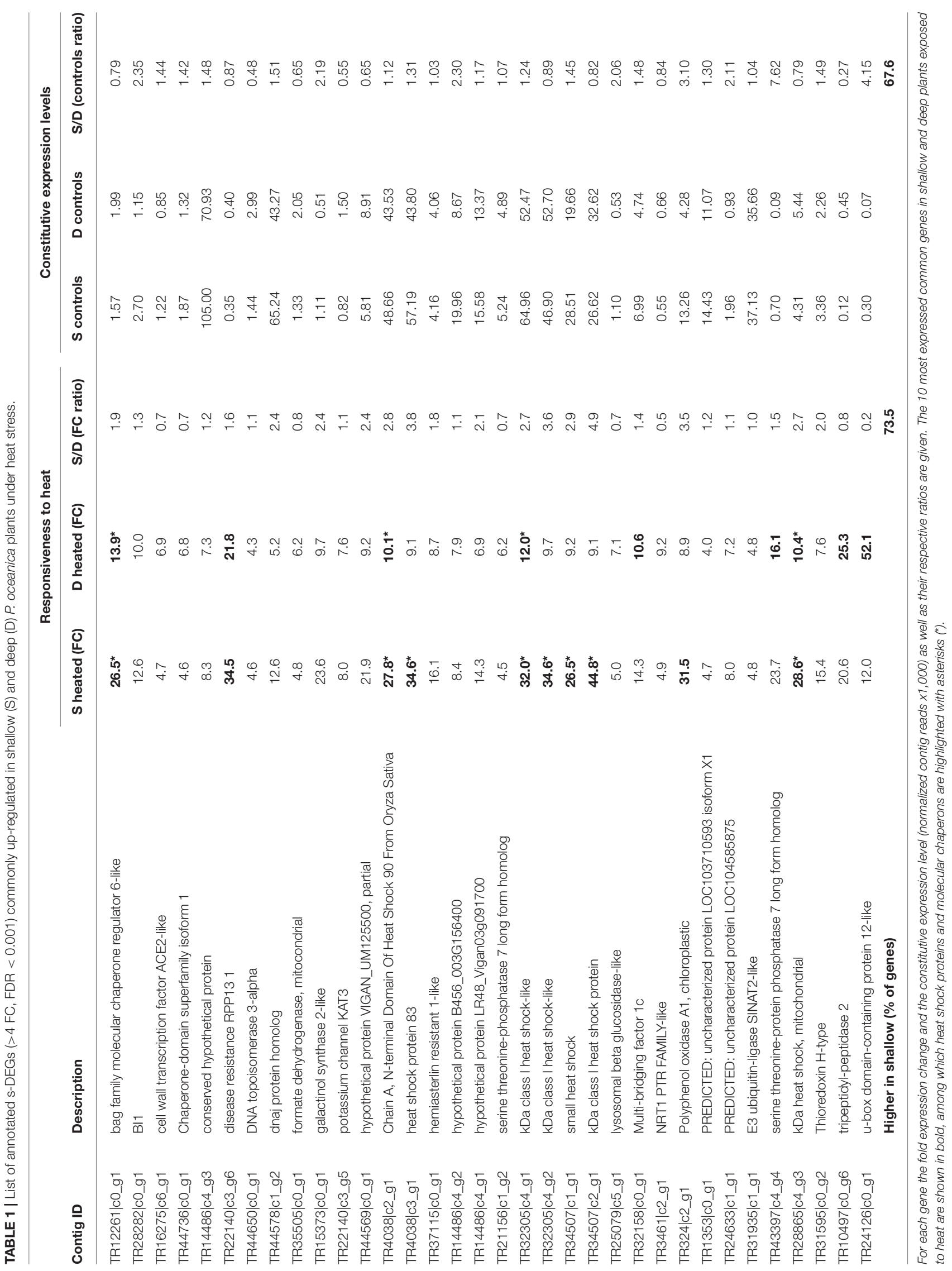


was $60 \%$ higher for up-regulated genes (182 vs. 72 ) and $13 \%$ higher for down-regulated ones (140 vs. 122) (Figure 3). These differences were even higher when considering genes that react to heat exclusively in plants of one of the two depths, mainly due to the much higher number of unique up-regulated genes in shallow plants (130 vs. 20$)$ since the number of unique down-regulated ones was almost similar (108 vs. 90).

This set of shallow-unique up-regulated genes was enriched (Fisher test, FDR < 0.05) in biological processes related, among others, to: (1) response to stress (oxidative stress, reactive oxygen species (ROS), endoplasmic reticulum (ER) stress); (2) biosynthesis and metabolism (tetrapyrroles, porphyrins, peptides); (3) regulation of homeostatic processes and growth; (4) photosynthesis and; (5) cellular respiration and respiratory electron transport chain (ETC; Figure 4A; Data S2C). The enrichment analysis of deep-unique up-regulated genes showed over-represented biological functions related to (1) amino acid and (2) sugar metabolic processes; (3) cellular energy metabolisms and (4) regulation of catalytic activity and protein metabolism, among others (Figure 4B; Data S2D).

Strongly up-regulated unique-shallow genes (s-DEGs, FC > 4 , FDR $<0.001)$ included a rich set of photosynthesis-related genes (Figure 5). They encode several proteins of the PSII complex such as the reaction center protein D2 (psbD), the light-harvesting proteins $\mathrm{CP} 43$ (psbC) and CP47 (psbB) and the cytochrome b559 alpha (psbE, essential for PSII assembly; Burda et al., 2003), as well as the two main subunits of PSI (psaA and psaB; Figure 5; Data S1Ca). This set also included genes that encode proteins of the photosynthetic ETC, such as the NADH-plastoquinone oxidoreductase subunits 2 and 5 (ndhB and ndhF), the cytochrome $\mathrm{C}$ heme attachment (ccsA) and two subunits of the cytochrome b6-f complex (petA and petB), together with several components of the ATP synthase complex (atpA, atpB, and atpF). Shallow plants also exclusively activated a strong transcription of a proton-translocating $\mathrm{NADH}$-quinone oxidoreductase of the mitochondrial respiratory ETC (complex I). Other s-DEGs were HSPs and molecular chaperons involved in protein folding such as hsp70 nucleotide exchange factor fes1, heat shock 70, heat shock cognate 70-1 and endoplasmin homologHSP90-7 (Figure 5; Data S1Cb).

Less strongly up-regulated unique-shallow genes (DEGs, $>2$ FC, FDR $<0.01$; Data $\mathrm{S} 1 \mathrm{Cb}$ ) also comprised the ribulose1,5-bisphosphate carboxylase/oxygenase large subunit ( $\mathrm{rbcL}$ ), a broad group of HSPs and molecular chaperons and two heat shock transcriptional factors (Figure 5). Other components of the mitochondrial respiratory ETC were also uniquely upregulated in shallow heated plants and included the amidA-like protein required for complex I function (Carilla-Latorre et al., 2010), the ubiquinol-cytochrome-c reductase (complex III) and the cytochrome $\mathrm{C}$ oxidase assembly factor 6 required for the efficient formation of the respiratory chain complex IV (Stroud et al., 2015). This only-shallow heat-activated set of genes also comprised few genes involved in the defense against oxidative stress such as L-ascorbate peroxidase 1 and 2 (APX1 and APX2) and a copper chaperone for the activation of superoxide dismutase (CCS), which is involved in the regulation of the heat stress response and plant thermotolerance (Guan et al., 2013).

Contrarily, deep heated plants did not exclusively activate genes involved in photosynthesis or in respiration and just a few HSPs and molecular chaperones (Figure 5; Data S1Ea and S1Eb). HSFs were neither included in the set of only deep up-regulated genes. The most highly expressed genes were not all included
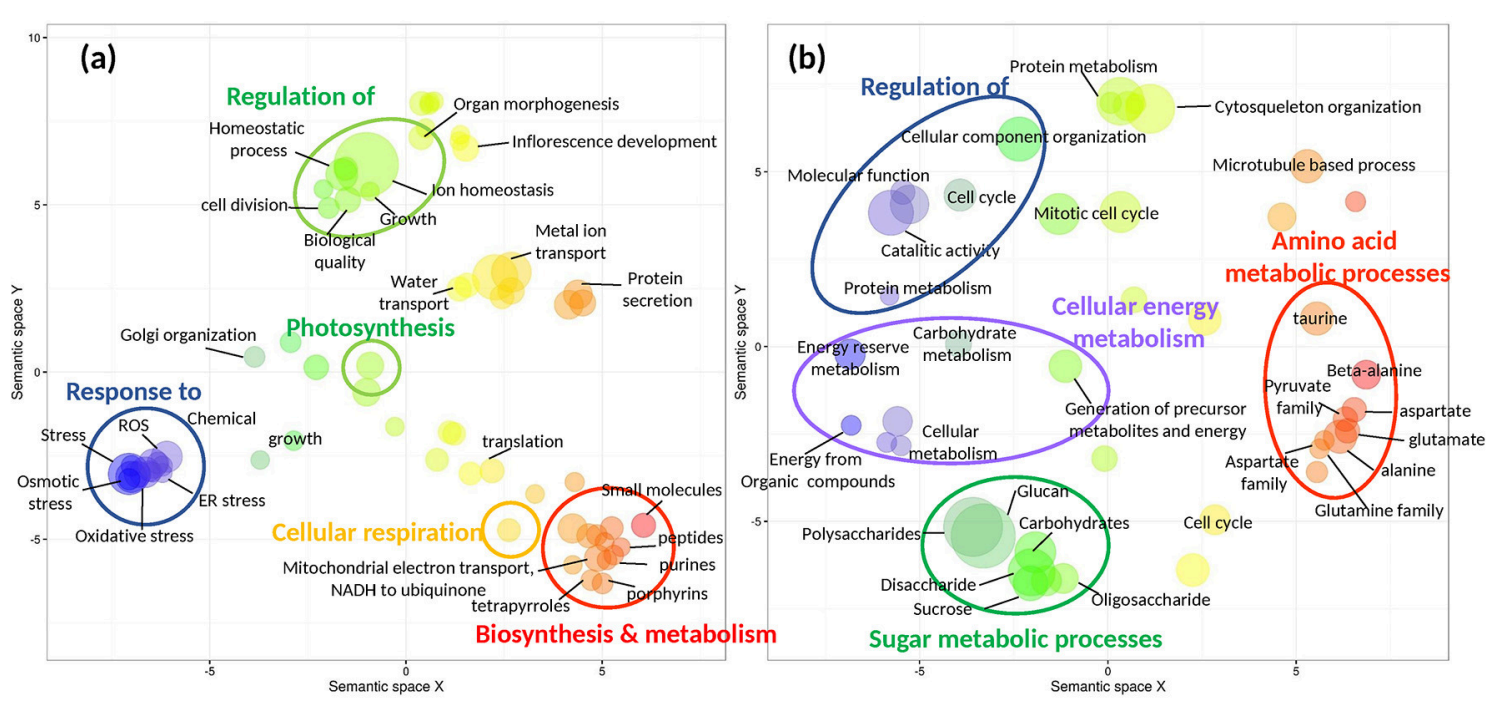

FIGURE 4 | Functional enrichment (Fisher test, false discovery rate $<0.001$ ) of heat-responsive shallow-unique (a) and deep-unique (b) s-DEGs (>4 FC, FDR < 0.001). Gene ontology (GO) terms of biological processes are represented by bubbles and plotted according to semantic similarities to other GO terms. Bubble size is proportional to $\log _{10} p$-values of the GO term, while color indicates semantic similarities. The two-dimensional semantic space was generated by the REVIGO web service with all GO terms found in the enrichment analyses. REVIGO's tables containing all gene functional categories represented in (a) and (b) are given as supplementary information (Data S3A and S3B). 


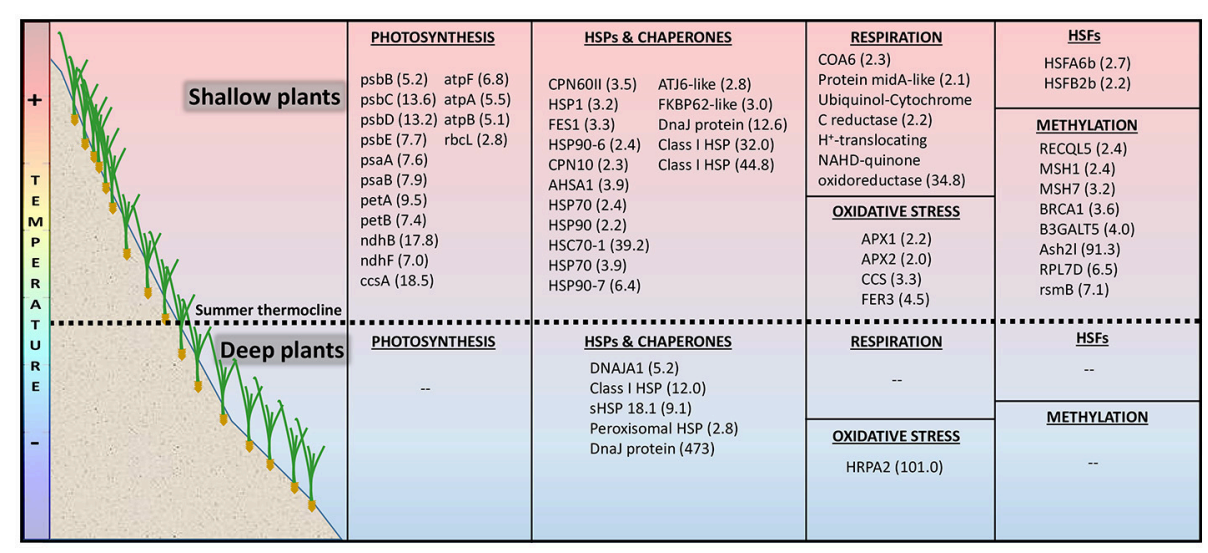

FIGURE 5 | Depth-specific heat transcriptomic response of Posidonia oceanica plants living above (shallow $5 \mathrm{~m}$ ) and below (deep $25 \mathrm{~m}$ ) the summer thermocline after being exposed to an increased temperature of $32^{\circ} \mathrm{C}$ during 5 days. The table shows differentially expressed genes (s-DEGs and DEGs) exclusively up-regulated in each of the two depths and their fold change in brackets.

in the functional categories illustrated in Figure 5. Among the others, a suppressor of gene silencing (436 FC) and a gene implicated in hydrogen peroxide catabolism (Peroxidase A2HRPA2, 101 FC) were present. Other deep up-regulated genes were related to proteolysis (subtilisin-like protease, $14 \mathrm{FC}$ ) and ubiquination (5.5 FC).

Both shallow and deep plants expressed TOP3, a gene related to DNA or histone methylation. Besides that one, shallow plants up-regulated 8 additional genes related to methylation (Figure 5) and down-regulated a gene involved in demethylation (Lysinespecific demethylase 5B, not in Figure 5).

After being allowed to recover from heat stress, shallow and deep plants showed respectively 17 and $38 \mathrm{DE}$ genes in respect to their controls (Figure 3; Data S1D and S1F), most of them being down-regulated (13 and 37, respectively) and including HSPs previously up-regulated during the heat exposure. At this time, there were no shared genes among plants from the two depths.

\section{Validation of RNAseq Results}

All tested genes assessed through RT-qPCR successfully validated RNA-seq results in shallow and deep genotypes, although showing minor differences in the magnitude of expression (i.e., fold changes; Figure S2). Results from both analyses were significantly correlated both in shallow $(N=12, r=0.89, p<$ $0.001)$ and deep $(N=12, r=0.90, p<0.001)$ genotypes.

\section{DISCUSSION}

The results of our transcriptomic analysis show that the iconic seagrass $P$. oceanica is able to overcome and recover from several days of severe heat. Species tolerance and resilience to heat stress is supported by the lack of transcriptomic evidences of lethal and permanent injury and by the complete photophysiological recovery. The activation of overall metabolic reprogramming seems to be the basis of the species' ability to withstand short-term heat stress. Some of the observed responses were aimed to restore the cell wall rigidity for ensuring the cell architecture and growth (Houston et al., 2016). They included the induction of the genes CEL3 (endoglucanase 9) and POK2 (phragmoplast orienting kinesin 2-like), required for cell wall organization (Robertson et al., 1997; Müller et al., 2006), and the reduction in the synthesis of glycerolipids, which is considered advantageous for the long-term acclimation of plants under increased temperatures (Higashi et al., 2015). Similar responses have been reported in the seagrass species $Z$. marina, where the enhanced expression of genes involved in cell-wall fortification buffer heat-stress and increase thermotolerance (Franssen et al., 2014; Jueterbock et al., 2016). The plants also show common mechanisms of recovery after the heat stress. Plants mostly shutdown processes involved in the thermal tolerance that were activated during exposure, as for instance HSPs. Moreover, the strong down-regulation of the genes LOX5 and AOS is possibly reflecting the de-activation of the stress signaling orchestrated by jasmonic acid (Ahmad et al., 2016). Our results also show important differences in the transcriptomic profiles of heated plants from different depths that reflect their different physiological tolerance and acclimation capacity to transitory warming and that might differentially affect plant survival under longer warming events. The observed transcriptomic differences were mainly based on: (i) the number of genes that exclusively react in plants of different depths and the physiological functions associated to them, (ii) the expression strength of the genes that commonly respond at both depths, and (iii) the constitutive levels of the commonly responsive genes.

\section{Differential Heat Sensitivity as Resulting from the Depth-Specific Transcriptomic Response to Heat}

In shallow plants, heat activated a greater number of genes reflecting the induction of a more complete heat response compared to deep plants, especially related to key physiological processes, such as photosynthesis and respiration. This also matches with the higher photosynthetic stability here observed 
in shallow-heated plants and with their higher respiratory acclimation previously reported (Marín-Guirao et al., 2016). Hence, gene activation seems to be more important than gene suppression in $P$. oceanica thermo-tolerance, as also supported by the presence of many shallow-unique up-regulated genes encoding proteins involved in acquired thermo-tolerance (e.g., HSPs, antioxidants). Shallow P. oceanica genotypes, in fact, showed transcriptomic evidence of suffering lower heatinduced physiological injury compared to deep genotypes. These were able to primarily up-regulate HSPs and molecular chaperons, investing in refolding reversibly denaturated proteins (Evans and Hofmann, 2012; Somero, 2012). Only shallow plants showed an intense transcription activity of a wide set of photosynthesis-related genes, likely to support a proper photosynthetic functioning and ATP production, in order to cope with the increased energy demand (Sharkey and Zhang, 2010; Liu et al., 2014). These genes were involved in all main phases of the photosynthetic process, from light harvesting to carbon fixation. They encode functional and structural proteins of all components of the thylakoid ETC, including the ATP synthase complex (Figure 6), which are known to be directly impacted by heat stress on terrestrial plants (Bita and Gerats, 2013). This strong induction could favor the turnover of relevant parts of the photosynthetic apparatus to maintain a correct electron flow and to protect thylakoid membranes from heat impairment (Song et al., 2014).

Plants from deep meadow portions, on the contrary, accumulated heat-induced damage on their photosystems reducing their photosynthetic efficiency and impairing the photosynthetic energy production. P. oceanica plants from deep meadows' portions sharply increase their respiratory activity during heat stress (Marín-Guirao et al., 2016), a metabolic response that allows to meet the increased demand of energy to support higher rates of biosynthesis and protein turnover (Lambers et al., 2008). The upregulation of ubiquination- and proteolysis-related genes suggests that, after 5 days at $32^{\circ} \mathrm{C}$, severe protein damage occurred, which required their removal by proteolytic processes. Indeed, the set of genes uniquely induced in deep plants included genes related to the ubiquitinmediated protein degradation, which is the principal mechanisms of protein catabolism to facilitate plant proteostasis under stressfull conditions (Kurepa et al., 2009). Deep plants were also functionally enriched in metabolic processes for obtaining extra energy from sugars and amino acids (Figure 4). The use of carbohydrate and amino acid reserves could cause long term metabolic and energetic imbalances, which likely translates into impaired fitness and survival (Alcoverro et al., 2001). Deepgrowing $P$. oceanica genotypes are, therefore, more fragile in response to extreme heat events, whose intensity and duration are predicted to increase in the coming decades as a result of climate change (Schar, 2016).

It has been shown that shallow P. oceanica plants have higher respiratory heat-acclimation capacity in respect to deep plants, which allow them to achieve respiratory homeostasis after several days of warming (Marín-Guirao et al., 2016). In the present study, shallow plants responded to heat with the induction of genes encoding respiratory enzymes of the mitochondrial
ETC (Figure 6). This reflects a preference for respiratory ATP production via the cytochrome pathway, which is more energyefficient than the alternative pathway favored in stressed plants through the enzyme AOX (Millenaar and Lambers, 2003). An induction of the cytochrome pathway was also shown in trees, where some species are able to maintain respiratory homeostasis along temperature gradients (Searle et al., 2011; Searle and Turnbull, 2011). Nevertheless, one of the main roles of the alternative pathway is to limit the formation of mitochondrial ROS, especially the superoxide radical $\left(\mathrm{O}_{2}^{-}\right)$that is mainly produced in complex III (Vanlerberghe, 2013; Deng et al., 2015). The promotion of the cytochrome pathway would therefore not only increase the energy yield of respiration but also ROS production. The accumulation of transcripts that activate and encode the most effective enzymatic antioxidants involved in scavenging of $\mathrm{O}_{2}^{-}$(Teotia and Singh, 2014), suggests that shallow plants also enhance their antioxidant defense, to protect themselves from an increased oxidative damage (Figure 6).

In synthesis, the combined induction of cytochromerelated respiratory enzymes and antioxidant enzymes should be functional, together with the maintenance of an efficient photosynthetic energy production, to the ability of shallow plants for thermal acclimation of respiration (Panda et al., 2008; Kühn et al., 2015).

\section{Expression Strength and Constitutive Levels of Heat-Responsive Genes}

In addition to a more complete transcriptomic response in term of number of heat-responsive genes, shallow P. oceanica plants also showed higher expression levels of most of the commonly activated genes. This response matches the one observed in the seagrass $Z$. marina, where plants from warm environments (i.e., southern populations) had higher thermal resilience and showed higher heat-inducible responses than plants from colder environments (northern populations; Franssen et al., 2014). When compared to deep P. oceanica genotypes, those growing at shallower depths also showed higher constitutive expression levels of heat responsive genes. The same pattern was recently observed in natural $P$. oceanica populations, confirming a more complex and complete constitutive response at shallower depth (Dattolo et al., 2013, 2014; Procaccini et al., 2017). Similar differences, but among individuals from contrasting latitudes, have been observed in different marine organisms, including other seagrasses (Franssen et al., 2014), corals (Barshis et al., 2013) and marine snails (Gleason and Burton, 2015), and have been suggested to be the result of an adaptive mechanism (or pre-adaptive defense strategy) that confers higher thermal tolerance to cope with frequent heat stress. The wide bathymetric distribution of $P$. oceanica meadows implies that shallow plants growing above the summer thermocline experience higher thermal stress levels than deep ones, similarly to the contrasting thermal environments experienced by organisms from latitudinal distant populations.

\section{Epigenetic Control of Heat Responses?}

We can speculate that life in a more stressful environment may have speeded up stress adaptive processes through 

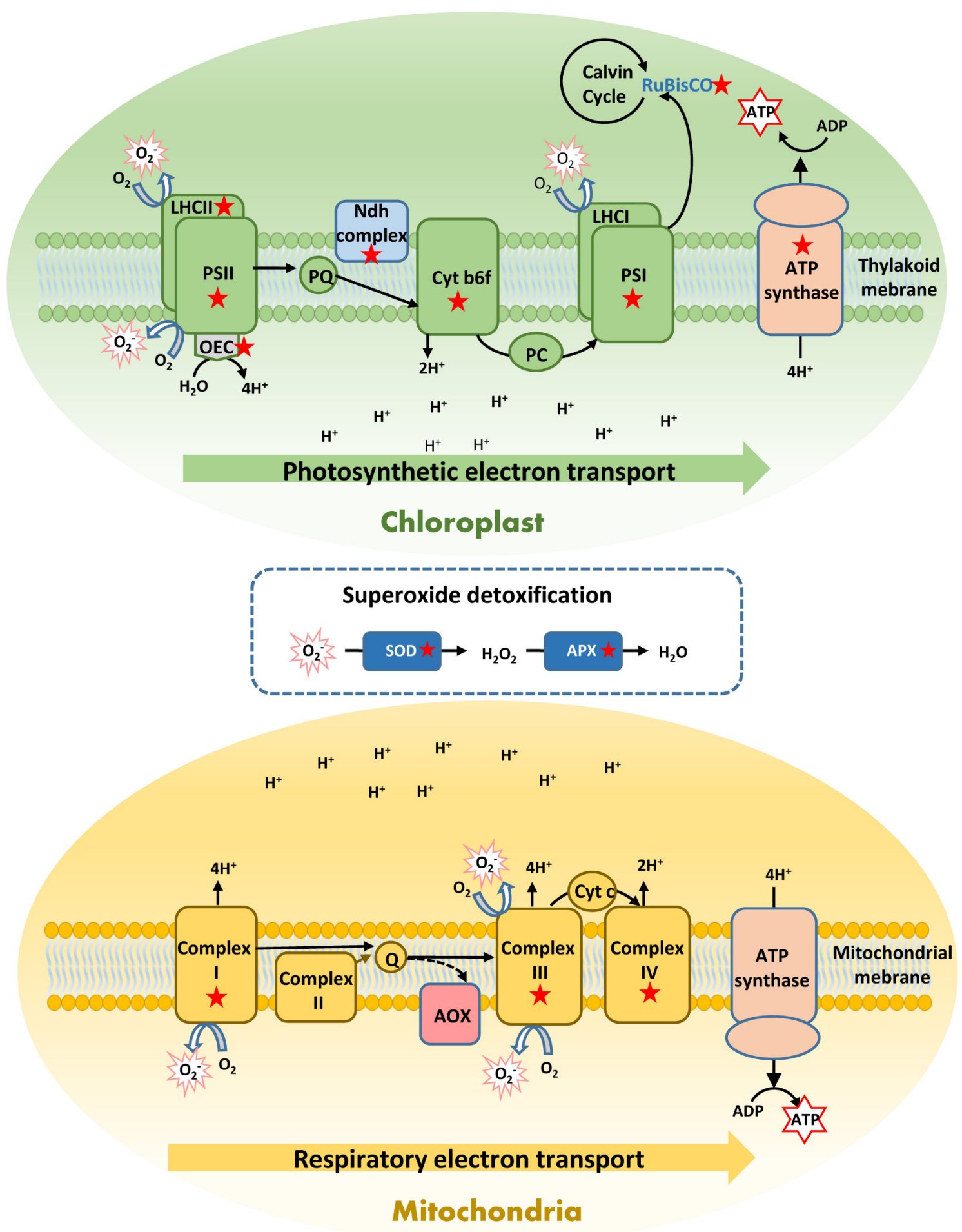

FIGURE 6 | Schematic representation of a respiratory and photosynthetic electron transport chains (ETC) showing the components in which heat-induced genes in shallow Posidonia oceanica plants are involved (labeled with a red star). Heating induced over-expression of a rich set of photosynthetic genes to improve the turnover of functional and structural proteins and maintain an efficient photosythetic performance and ATP production. In addition, heat stress uniquely induced in shallow plants over-expression of respiratory genes related to the mitochondrial ETC complexes I, III, and IV, which reflect the activation of the cytochrome pathway for respiratory ATP production. Although this pathway is more energy-efficient than the alternative oxidase pathway (AOX), it is also the main producer of mitochondrial ROS, especially the superoxide radical $\left(\mathrm{O}_{2}^{-}\right)$. To protect against oxidative damage these shallow plants activated the ROS-scavenging enzymes superoxide dismutase (SOD) and ascorbate peroxidase (APX). These exclusive responses of shallow plants conferred them higher heat tolerance respect to deep plants, and enabled them for an efficient energy production to cover the energetic cost associate to heat stress. A complete list of these genes with their corresponding fold change is shown in Figure 5 and in Data S1. 
epigenetic mechanisms such as DNA methylation and chromatin remodeling. Stress-induced epigenetic mechanisms are crucial in activating the plants' immediate response to stress, as well as in the establishment of short- and long-term adaptation, due to their important role in regulating the expression of stress-related genes (Liu et al., 2015). Consequently, the exclusive induction of genes involved in DNA and histone methylation in shallow heated plants could support the role of this processes in P. oceanica, favoring their efficient short-term heat acclimation through the successful activation and regulation of heat-responsive genes (Correia et al., 2013). Accordingly, only these shallow plants showed the activation of heat shock factors, which are transcriptional activators of heat shock genes (Kotak et al., 2007; von Koskull-Doring et al., 2007) and that mutually progress with epigenetic processes in regulating the abiotic stress responses in plants. These epigenetic modifications can be involved in the evolution of adaptive strategies and speciation (Flatscher et al., 2012; Smith et al., 2016) and potentially also in the genetic disjunction existing between shallow and deep meadow stands in P. oceanica (Migliaccio et al., 2005). Epigenetic modifications could also be at the basis of the survival of millenary clones of the species in the face of the environmental changes they have experienced along their evolutionary history (Arnaud-Haond et al., 2012). Indeed, epigenetic variation is thought to be of particular importance to provide ecological and evolutionary adaptation to clonal plants, being the likely explanation to their widespread success and long-term persistence (Dodd and Douhovnikoff, 2016; Latzel et al., 2016). Understanding the role of epigenetic processes in enhancing phenotypic plasticity in $P$. oceanica can be very important to improve our ability in predicting the future of this key species. Plasticity, in fact, provides a buffer against rapid climatic changes and also assists the rapid adaptation of the species to the ongoing climatic change (Merila and Hendry, 2014).

Our experimental procedure allowed us to identify key mechanisms involved the thermal tolerance of $P$. oceanica. However, since we did not simulate a realistic summer heatwave in terms of rates and duration of warming, we cannot conclude that this keystone species is able to overcome the heat stress produced during these natural extreme thermal events. In a global change scenario, in which the Mediterranean Sea is

\section{REFERENCES}

Ahmad, P., Rasool, S., Gul, A., Sheikh, S. A., Akram, N. A., Ashraf, M., et al. (2016). Jasmonates: multifunctional roles in stress tolerance. Front. Plant Sci. 7:813. doi: $10.3389 /$ fpls.2016.00813

Alcoverro, T., Manzanera, M., and Romero, J. (2001). Annual metabolic carbon balance of the seagrass Posidonia oceanica: the importance of carbohydrate reserves. Mar. Ecol. Prog. Ser. 211, 105-116. doi: 10.3354/meps211105

Altschul, S. F., Madden, T. L., Schäffer, A. A., Zhang, J., Zhang, Z., Miller, W., et al. (1997). Gapped BLAST and PSI-BLAST: a new generation of protein database search programs. Nucleic Acids Res. 25, 3389-3402. doi: 10.1093/nar/25.17.3389

Andrews, S. (2010). FastQC: A Quality Control Tool for High Throughput Sequence Data. Available online at: http://www.bioinformatics.babraham.ac.uk/projects/ fastqc (Accessed June 1, 2016). undergoing increases in the duration of extreme warming events, the effect of heat stress on $P$. oceanica meadows could be dramatic (Jordà et al., 2012). P. oceanica plants from above and below the summer thermocline have differential resilience to heat and meadow portions from different depths are expected to be differentially impacted by these extreme events. Shallow plants, living in a more unstable thermal environment, optimized phenotype variation in response to warming. These plants showed a pre-adaptation of genes in anticipation of stress and the exclusive induction of genes involved in epigenetic mechanisms. Shallow plants also showed a stronger activation of heat-responsive genes and the exclusive activation of genes involved in molecular mechanisms that are behind their higher photosynthetic stability and respiratory acclimation.

\section{AUTHOR CONTRIBUTIONS}

LM, JR, and GP planned and designed the study. LM and ED performed the heat-stress experiment, samples processing and lab work. LE conducted bioinformatics and data analysis. LM led the writing of the paper with contributions from the rest of authors. All Authors reviewed the manuscript.

\section{ACKNOWLEDGMENTS}

The European Union and the Spanish Government funded this study through the HEATGRASS (Tolerance to heat stress induced by climate change in the seagrass Posidonia oceanica, \#624035) and RECCAM (Seagrass Meadows resilience to global warming: an analysis based on responses at ecophysiological, population and ecosystem levels, CTM2013-48027-C3-2-R) projects. ED was supported by the Italian MIUR Flagship project RITMARE. LM was supported by a Marie-Curie Fellowship (FP7-PEOPLE-IEF-2013; HEATGRASS Project). Special thanks are given to Rocio Garcia Munoz and Jaime Bernardeau Esteller for the help in field and laboratory plant sampling.

\section{SUPPLEMENTARY MATERIAL}

The Supplementary Material for this article can be found online at: http://journal.frontiersin.org/article/10.3389/fpls.2017. 01142/full\#supplementary-material 
Boeckx, T., Winters, A. L., Webb, K. J., and Kingston-Smith, A. H. (2015). Polyphenol oxidase in leaves; is there any significance to the chloroplastic localization? J. Exp. Bot. 66, 3571-3579. doi: 10.1093/jxb/erv141

Bolger, A. M., Lohse, M., and Usadel, B. (2014). Trimmomatic: a flexible trimmer for illumina sequence data. Bioinformatics 30, 2114-2120. doi: 10.1093/bioinformatics/btu170

Brestic, M., and Zivcak, M. (2013). "PSII Fluorescence techniques for measurement of drought and high temperature stress signal in crop plants: protocols and applications," in Molecular Stress Physiology of Plants, eds R. G. Rout and B. A. Das (Springer), 87-131.

Burda, K., Kruk, J., Borgstädt, R., Stanek, J., Strzaka, K., Schmid, G. H., et al. (2003). Mössbauer studies of the non-heme iron and cytochrome b559 in a Chlamydomonas reinhardtii PSI- mutant and their interactions with $\alpha$-tocopherol quinone. FEBS Lett. 535, 159-165. doi: 10.1016/S0014-5793(02)03895-4

Campbell, S. J., McKenzie, L. J., and Kerville, S. P. (2006). Photosynthetic responses of seven tropical seagrasses to elevated seawater temperature. J. Exp. Mar. Biol. Ecol. 330, 455-468. doi: 10.1016/j.jembe.2005.09.017

Carilla-Latorre, S., Gallardo, M. E., Annesley, S. J., Calvo-Garrido, J., Graña, O., Accari, S. L., et al. (2010). MidA is a putative methyltransferase that is required for mitochondrial complex I function. J. Cell Sci. 123, 1674-1683. doi: $10.1242 /$ jcs. 066076

Collier, C. J., Uthicke, S., and Waycott, M. (2011). Thermal tolerance of two seagrass species at contrasting light levels: implications for future distribution in the Great Barrier Reef. Limnol. Oceanogr. 56, 2200-2210. doi: 10.4319/lo.2011.56.6.2200

Collier, C. J., and Waycott, M. (2014). Temperature extremes reduce seagrass growth and induce mortality. Mar. Pollut. Bull. 83, 483-490. doi: 10.1016/j.marpolbul.2014.03.050

Conesa, A., Götz, S., García-Gómez, J. M., Terol, J., Talón, M., and Robles, M. (2005). Blast2GO: a universal tool for annotation, visualization and analysis in functional genomics research. Bioinformatics 21, 3674-3676. doi: 10.1093/bioinformatics/bti610

Correia, B., Valledor, L., Meijón, M., Rodriguez, J. L., Dias, M. C., Santos, C., et al. (2013). Is the interplay between Epigenetic Markers related to the acclimation of cork oak plants to high temperatures? PLoS ONE 8:e53543. doi: 10.1371/journal.pone.0053543

Costanza, R., de Groot, R., Sutton, P., van der Ploeg, S., Anderson, S. J., Kubiszewski, I., et al. (2014). Changes in the global value of ecosystem services. Global Environ. Change 26, 152-158. doi: 10.1016/j.gloenvcha.2014. 04.002

Dattolo, E., Gu, J., Bayer, P. E., Mazzuca, S., Serra, I. A., Spadafora, A., et al. (2013). Acclimation to different depths by the marine angiosperm Posidonia oceanica: transcriptomic and proteomic profiles. Front. Plant. Sci. 4:195. doi: $10.3389 /$ fpls.2013.00195

Dattolo, E., Marín-Guirao, L., Ruiz, J. M., and Procaccini, G. (2017). Long-term acclimation to reciprocal light conditions suggests depth-related selection in the marine foundation species Posidonia oceanica. Ecol. Evol. 7, 1148-1164. doi: $10.1002 /$ ece3.2731

Dattolo, E., Ruocco, M., Brunet, C., Lorenti, M., Lauritano, C., D'Esposito, D., et al. (2014). Response of the seagrass Posidonia oceanica to different light environments: insights from a combined molecular and photo-physiological study. Mar. Environ. Res. 101, 225-236. doi: 10.1016/j.marenvres.2014.07.010

Davey, P. A., Pernice, M., Sablok, G., Larkum, A., Lee, H. T., Golicz, A., et al. (2016). The emergence of molecular profiling and omics techniques in seagrass biology; furthering our understanding of seagrassses. Funct. Integr. Genomics 16, 465-480. doi: 10.1007/s10142-016-0501-4

Deng, X.-G., Zhu, T., Zhang, D.-W., and Lin, H.-H. (2015). The alternative respiratory pathway is involved in brassinosteroid-induced environmental stress tolerance in Nicotiana benthamiana. J. Exp. Bot. 66, 6219-6232. doi: $10.1093 / \mathrm{jxb} / \mathrm{erv} 328$

Díaz-Almela, E., Marbà, N., Martínez, R., Santiago, R., and Duarte, C. M. (2009). Seasonal dynamics of Posidonia oceanica in Magalluf Bay (Mallorca, Spain): temperature effects on seagrass mortality. Limnol. Oceanogr. 54, 2170-2182. doi: 10.4319/lo.2009.54.6.2170

Dodd, R. S., and Douhovnikoff, V. (2016). Adjusting to global change through clonal growth and epigenetic variation. Front. Ecol. Evol. 4:86. doi: $10.3389 /$ fevo.2016.00086
Evans, T. G., and Hofmann, G. E. (2012). Defining the limits of physiological plasticity: how gene expression can assess and predict the consequences of ocean change. Philos. Trans. R. Soc. Lond. B Biol. Sci. 367, 1733-1745. doi: 10.1098/rstb.2012.0019

Flatscher, R., Frajman, B., Schönswetter, P., and Paun, O. (2012). Environmental heterogeneity and phenotypic divergence: can heritable epigenetic variation aid speciation? Gen. Res. Inter. 2012, 9. doi: 10.1155/2012/698421

Franssen, S. U., Gu, J., Bergmann, N., Winters, G., Klostermeier, U. C., Rosenstiel, P., et al. (2011). Transcriptomic resilience to global warming in the seagrass Zostera marina, a marine foundation species. Proc. Natl. Acad. Sci. U.S.A. 108, 19276-19281. doi: 10.1073/pnas.1107680108

Franssen, S. U., Gu, J., Winters, G., Huylmans, A. K., Wienpahl, I., Sparwel, M., et al. (2014). Genome-wide transcriptomic responses of the seagrasses Zostera marina and Nanozostera noltii under a simulated heatwave confirm functional types. Mar. Genomics 15, 65-73. doi: 10.1016/j.margen.2014. 03.004

Gleason, L. U., and Burton, R. S. (2015). RNA-seq reveals regional differences in transcriptome response to heat stress in the marine snail Chlorostoma funebralis. Mol. Ecol. 24, 610-627. doi: 10.1111/mec.13047

Grabherr, M. G., Haas, B. J., Yassour, M., Levin, J. Z., Thompson, D. A., Amit, I., et al. (2011). Full-length transcriptome assembly from RNA-Seq data without a reference genome. Nat. Biotech. 29, 644-652. doi: 10.1038/n bt. 1883

Gu, J., Weber, K., Klemp, E., Winters, G., Franssen, S. U., Wienpahl, I., et al. (2012). Identifying core features of adaptive metabolic mechanisms for chronic heat stress attenuation contributing to systems robustness. Integr. Biol. 4, 480-493. doi: $10.1039 / \mathrm{c} 2 \mathrm{ib} 00109 \mathrm{~h}$

Guan, Q., Lu, X., Zeng, H., Zhang, Y., and Zhu, J. (2013). Heat stress induction of miR398 triggers a regulatory loop that is critical for thermotolerance in Arabidopsis. Plant J. 74, 840-851. doi: 10.1111/tpj.12169

Haas, B. J., Papanicolaou, A., Yassour, M., Grabherr, M., Blood, P. D., Bowden, J., et al. (2013). De novo transcript sequence reconstruction from RNA-seq using the Trinity platform for reference generation and analysis. Nat. Protocols 8 , 1494-1512. doi: 10.1038/nprot.2013.084

Higashi, Y., Okazaki, Y., Myouga, F., Shinozaki, K., and Saito, K. (2015). Landscape of the lipidome and transcriptome under heat stress in Arabidopsis thaliana. Sci. Rep. 5:10533. doi: 10.1038/srep10533

Hoegh-Guldberg, O., and Bruno, J. F. (2010). The impact of climate change on the world's marine ecosystems. Science 328, 1523-1528. doi: 10.1126/science.1189930

Houston, K., Tucker, M. R., Chowdhury, J., Shirley, N., and Little, A. (2016). The plant cell wall: a complex and dynamic structure as revealed by the responses of genes under stress conditions. Front. Plant Sci. 7:984. doi: 10.3389/fpls.2016.00984

Jordà, G., Marbà, N., and Duarte, C. M. (2012). Mediterranean seagrass vulnerable to regional climate warming. Nat. Clim. Change 2, 821-824. doi: $10.1038 /$ nclimate 1533

Jueterbock, A., Franssen, S. U., Bergmann, N., Gu, J., Coyer, J. A., Reusch, T. B. H., et al. (2016). Phylogeographic differentiation versus transcriptomic adaptation to warm temperatures in Zostera marina, a globally important seagrass. Mol. Ecol. 25, 5396-5411. doi: 10.1111/mec.13829

Koch, M., Bowes, G., Ross, C., and Zhang, X. H. (2013). Climate change and ocean acidification effects on seagrasses and marine macroalgae. Glob. Chang. Biol. 19, 103-132. doi: 10.1111/j.1365-2486.2012.02791.x

Kopylova, E., Noé, L., and Touzet, H. (2012). SortMeRNA: fast and accurate filtering of ribosomal RNAs in metatranscriptomic data. Bioinformatics 28, 3211-3217. doi: 10.1093/bioinformatics/bts611

Kotak, S., Larkindale, J., Lee, U., von Koskull-Doring, P., Vierling, E., and Scharf, K. D. (2007). Complexity of the heat stress response in plants. Curr. Opin. Plant Biol. 10, 310-316. doi: 10.1016/j.pbi.2007.04.011

Kühn, K., Yin, G., Duncan, O., Law, S. R., Kubiszewski-Jakubiak, S., Kaur, P., et al. (2015). Decreasing electron flux through the Cytochrome and/or alternative respiratory pathways triggers common and distinct cellular responses dependent on growth conditions. Plant Physiol. 167, 228-250. doi: 10.1104/pp.114.249946

Kurepa, J., Wang, S., Li, Y., and Smalle, J. (2009). Proteasome regulation, plant growth and stress tolerance. Plant Signal. Behav. 4, 924-927. doi: $10.4161 /$ psb.4.10.9469 
Lambers, H., Chapin, F. S., and Pons, T. L. (2008). Plant Physiological Ecology. New York, NY: Springer.

Langmead, B., Trapnell, C., Pop, M., and Salzberg, S. L. (2009). Ultrafast and memory-efficient alignment of short DNA sequences to the human genome. Genome Biol. 10, 1-10. doi: 10.1186/gb-2009-10-3-r25

Latzel, V., Rendina González, A. P., and Rosenthal, J. (2016). Epigenetic memory as a basis for intelligent behavior in clonal plants. Front. Plant Sci. 7:1354. doi: 10.3389/fpls.2016.01354

Leakey, A. D. B., Ainsworth, E. A., Bernard, S. M., Markelz, R. J. C., Ort, D. R., Placella, S. A., et al. (2009). Gene expression profiling: opening the black box of plant ecosystem responses to global change. Glob. Change Biol. 15, 1201-1213. doi: $10.1111 / j .1365-2486.2008 .01818 . x$

Lee, K.-S., Park, S. R., and Kim, Y. K. (2007). Effects of irradiance, temperature, and nutrients on growth dynamics of seagrasses: a review. J. Exp. Mar. Biol. Ecol. 350, 144-175. doi: 10.1016/j.jembe.2007.06.016

Les, D. H., Cleland, M. A., and Waycott, M. (1997). Phylogenetic studies in alismatidae, II: evolution of marine angiosperms (Seagrasses) and hydrophily. Syst. Bot. 22, 443-463. doi: 10.2307/2419820

Li, B., and Dewey, C. N. (2011). RSEM: accurate transcript quantification from RNA-Seq data with or without a reference genome. BMC Bioinform. 12, 1-16. doi: 10.1186/1471-2105-12-323

Liu, G.-T., Ma, L., Duan, W., Wang, B.-C., Li, J.-H., Xu, H.-G., et al. (2014). Differential proteomic analysis of grapevine leaves by iTRAQ reveals responses to heat stress and subsequent recovery. BMC Plant Biol. 14:110. doi: $10.1186 / 1471-2229-14-110$

Liu, H.-T., Li, G.-L., Chang, H. U. I., Sun, D.-Y., Zhou, R.-G., and Li, B. (2007). Calmodulin-binding protein phosphatase PP7 is involved in thermotolerance in Arabidopsis. Plant Cell Environ. 30, 156-164. doi: 10.1111/j.1365-3040.2006.01613.x

Liu, J., Feng, L., Li, J., and He, Z. (2015). Genetic and epigenetic control of plant heat responses. Front. Plant Sci. 6:267. doi: 10.3389/fpls.2015.00267

Marbá, N., and Duarte, C. M. (2010). Mediterranean warming triggers seagrass (Posidonia oceanica) shoot mortality. Glob. Chang. Biol. 16, 2366-2375. doi: $10.1111 /$ j.1365-2486.2009.02130.x

Marín-Guirao, L., Ruiz, J. M., Dattolo, E., Garcia-Munoz, R., and Procaccini, G. (2016). Physiological and molecular evidence of differential shortterm heat tolerance in Mediterranean seagrasses. Sci. Rep. 6:28615. doi: $10.1038 /$ srep 28615

Mazzuca, S., Bjork, M., Beer, S., Felisberto, P., Gobert, S., Procaccini, G., et al. (2013). Establishing research strategies, methodologies and technologies to link genomics and proteomics to seagrass productivity, community metabolism, and ecosystem carbon fluxes. Front. Plant Sci. 4:38. doi: $10.3389 /$ fpls.2013.00038

Merila, J., and Hendry, A. P. (2014). Climate change, adaptation, and phenotypic plasticity: the problem and the evidence. Evol. Appl. 7, 1-14. doi: 10.1111/eva.12137

Migliaccio, M., Martino, F. D., Silvestre, F., and Procaccini, G. (2005). Meadowscale genetic structure in Posidonia oceanica. Mar. Ecol. Prog. Ser. 304, 55-65. doi: 10.3354/meps304055

Millenaar, F. F., and Lambers, H. (2003). The alternative oxidase: in vivo regulation and function. Plant Biol. 5, 2-15. doi: 10.1055/s-2003-37974

Moore, K. A., Shields, E. C., and Parrish, D. B. (2014). Impacts of varying estuarine temperature and light conditions on Zostera marina (Eelgrass) and its interactions with Ruppia maritima (Widgeongrass). Estuar. Coast. 37, 20-30. doi: $10.1007 /$ s12237-013-9667-3

Müller, S., Han, S., and Smith, L. G. (2006). Two Kinesins are involved in the spatial control of cytokinesis in Arabidopsis thaliana. Curr. Biol. 16, 888-894. doi: 10.1016/j.cub.2006.03.034

Olsen, J. L., Rouzé, P., Verhelst, B., Lin, Y.-C., Bayer, T., Collen, J., et al. (2016). The genome of the seagrass Zostera marina reveals angiosperm adaptation to the sea. Nature 530, 331-335. doi: 10.1038/nature 16548

Panda, S. K., Yamamoto, Y., Kondo, H., and Matsumoto, H. (2008). Mitochondrial alterations related to programmed cell death in tobacco cells under aluminium stress. C. R. Biol. 331, 597-610. doi: 10.1016/j.crvi.2008. 04.008

Pedersen, O., Colmer, T. D., Borum, J., Zavala-Perez, A., and Kendrick, G. A. (2016). Heat stress of two tropical seagrass species during low tides - impact on underwater net photosynthesis, dark respiration and diel in situ internal aeration. New Phytol. 210, 1207-1218. doi: 10.1111/nph.13900

Procaccini, G., Beer, S., Björk, M., Olsen, J., Mazzuca, S., and Santos, R. (2012). Seagrass ecophysiology meets ecological genomics: are we ready? Mar. Ecol. 33, 522-527. doi: 10.1111/j.1439-0485.2012.00518.x

Procaccini, G., Ruocco, M., Marín-Guirao, L., Dattolo, E., Brunet, C., D’Esposito, D., et al. (2017). Depth-specific fluctuations of gene expression and protein abundance modulate the photophysiology in the seagrass Posidonia oceanica. Sci. Rep. 7:42890. doi: 10.1038/srep42890

R Core Team (2015). R: A Language and Environment for Statistical Computing. Vienna: R Foundation for Statistical Computing.

Ralph, P. J. (1998). Photosynthetic response of laboratory-cultured Halophila ovalis to thermal stress. Mar. Ecol. Prog. Ser. 171, 123-130. doi: 10.3354/meps171123

Ralph, P. J. (1999). Photosynthetic response of Halophila ovalis (R. Br.) Hook. f. to combined environmental stress. Aquat. Bot. 65, 83-96. doi: 10.1016/S0304-3770(99)00033-9

Robertson, D., Mitchell, G. P., Gilroy, J. S., Gerrish, C., Bolwell, G. P., and Slabas, A. R. (1997). Differential extraction and protein sequencing reveals major differences in patterns of primary cell wall proteins from plants. J. Biol. Chem. 272, 15841-15848. doi: 10.1074/jbc.272.25.15841

Robinson, M. D., McCarthy, D. J., and Smyth, G. K. (2010). edgeR: a Bioconductor package for differential expression analysis of digital gene expression data. Bioinformatics 26, 139-140. doi: 10.1093/bioinformatics/btp616

Ruiz, J. M., Bernardeau, J., García-Muñoz, R., and Ramos-Segura, A. (2015). Monitoring network of Posidonia oceanica meadows and climate change in the region of Murcia: period 2004-2015. Murcia: Seagrass Ecology Group, Spanish Institute of Oceanography, Oceanography Center of Murcia, 152. Available online at: http://hdl.handle.net/10508/10139 (Accessed June 1, 2017).

Schar, C. (2016). Climate extremes: the worst heat waves to come. Nat. Clim. Change 6, 128-129. doi: 10.1038/nclimate2864

Searle, S. Y., Bitterman, D. S., Thomas, S., Griffin, K. L., Atkin, O. K., and Turnbull, M. H. (2011). Respiratory alternative oxidase responds to both low- and hightemperature stress in Quercus rubra leaves along an urban-rural gradient in New York. Funct. Ecol. 25, 1007-1017. doi: 10.1111/j.1365-2435.2011. 01875.X

Searle, S. Y., and Turnbull, M. H. (2011). Seasonal variation of leaf respiration and the alternative pathway in field-grown Populus canadensis. Physiol. Plant. 141, 332-342. doi: 10.1111/j.1399-3054.2010.01442.x

Sharkey, T. D., and Zhang, R. (2010). High temperature effects on electron and proton circuits of photosynthesis. J. Integr. Plant Biol. 52, 712-722. doi: 10.1111/j.1744-7909.2010.00975.x

Smith, T. A., Martin, M. D., Nguyen, M., and Mendelson, T. C. (2016). Epigenetic divergence as a potential first step in darter speciation. Mol. Ecol. 25, 1883-1894. doi: 10.1111/mec.13561

Somero, G. N. (2012). The physiology of global change: linking patterns to mechanisms. Ann. Rev. Mar. Sci. 4, 39-61. doi: 10.1146/annurev-marine-120710-100935

Song, Y., Chen, Q., Ci, D., Shao, X., and Zhang, D. (2014). Effects of high temperature on photosynthesis and related gene expression in poplar. $B M C$ Plant Biol. 14:111. doi: 10.1186/1471-2229-14-111

Stroud, D. A., Maher, M. J., Lindau, C., Vögtle, F.-N., Frazier, A. E., Surgenor, E., et al. (2015). COA6 is a mitochondrial complex IV assembly factor critical for biogenesis of mtDNA-encoded COX2. Hum. Mol. Genet. 24, 5404-5415. doi: $10.1093 / \mathrm{hmg} / \mathrm{ddv} 265$

Supek, F., and Bošnjak, M., Škunca, N., and Šmuc, T. (2011). REVIGO summarizes and visualizes long lists of gene ontology terms. PLoS ONE 6:e21800. doi: 10.1371/journal.pone.0021800

Teotia, S., and Singh, D. (2014). "Oxidative stress in plants and its management," in: Approaches to Plant Stress and their Management, eds R. K. Gaur and P. Sharma (New Delhi, Springer India), 227-253.

Thomson, J. A., Burkholder, D. A., Heithaus, M. R., Fourqurean, J. W., Fraser, M. W., Statton, J., et al. (2015). Extreme temperatures, foundation species, and abrupt ecosystem change: an example from an iconic seagrass ecosystem. Glob. Change Biol. 21, 1463-1474. doi: 10.1111/gcb.12694

Tomasello, A., Di Maida, G., Calvo, S., Pirrotta, M., Borra, M., and Procaccini, G. (2009). Seagrass meadows at the extreme of environmental tolerance: the case of Posidonia oceanica in a semi-enclosed coastal lagoon. Mar. Ecol. 30, 288-300. doi: 10.1111/j.1439-0485.2009.00285.x 
Vanlerberghe, G. (2013). Alternative oxidase: a mitochondrial respiratory pathway to maintain metabolic and signaling homeostasis during abiotic and biotic stress in plants. Int. J. Mol. Sci. 14:6805. doi: 10.3390/ijms14046805

von Koskull-Doring, P., Scharf, K. D., and Nover, L. (2007). The diversity of plant heat stress transcription factors. Trends Plant Sci. 12, 452-457. doi: 10.1016/j.tplants.2007.08.014

Wahid, A., Gelani, S., Ashraf, M., and Foolad, M. (2007). Heat tolerance in plants: an overview. Environ. Exp. Bot. 61, 199-223. doi: 10.1016/j.envexpbot.2007.05.011

Waycott, M., Duarte, C. M., Carruthers, T. J., Orth, R. J., Dennison, W. C., Olyarnik, S., et al. (2009). Accelerating loss of seagrasses across the globe threatens coastal ecosystems. Proc. Natl. Acad. Sci. U.S.A. 106, 12377-12381. doi: $10.1073 /$ pnas.0905620106

Wickham, H. (2010). ggplot2: Elegant Graphics for Data Analysis. New York, NY: Springer.

Winters, G., Nelle, P., Fricke, B., Rauch, G., and Reusch, T. B. H. (2011). Effects of a simulated heat wave on photophysiology and gene expression of high- and low-latitude populations of Zostera marina. Mar. Ecol. Prog. Ser. 435, 83-95. doi: 10.3354/meps09213

Wissler, L., Codoner, F. M., Gu, J., Reusch, T. B., Olsen, J. L., Procaccini, G., et al. (2011). Back to the sea twice: identifying candidate plant genes for molecular evolution to marine life. BMC Evol. Biol. 11:8. doi: 10.1186/1471-21 48-11-8

Yang, H. R., Liu, H. T., Tang, K., and Huang, W. D. (2011). Role of lipoxygenase and allene oxide synthase in wound-inducible defense response of pea. Russ. J. Plant Physiol. 58, 238-247. doi: 10.1134/S1021443711 020233

Zdobnov, E. M., and Apweiler, R. (2001). InterProScan - an integration platform for the signature-recognition methods in InterPro. Bioinformatics 17, 847-848. doi: 10.1093/bioinformatics/17.9.847

Conflict of Interest Statement: The authors declare that the research was conducted in the absence of any commercial or financial relationships that could be construed as a potential conflict of interest.

Copyright (c) 2017 Marín-Guirao, Entrambasaguas, Dattolo, Ruiz and Procaccini. This is an open-access article distributed under the terms of the Creative Commons Attribution License (CC BY). The use, distribution or reproduction in other forums is permitted, provided the original author(s) or licensor are credited and that the original publication in this journal is cited, in accordance with accepted academic practice. No use, distribution or reproduction is permitted which does not comply with these terms. 